\title{
Is there still need for microelectrode recording now the subthalamic nucleus can be well visualized with high field and ultrahigh MR imaging?
}

\author{
Ersoy Kocabicak 1, 2, 3, Onur Alptekin ${ }^{2}$, Linda Ackermans ${ }^{1}$, Pieter Kubben ${ }^{1}$, Mark Kuijf ${ }^{4}$, \\ Erkan Kurt ${ }^{5}$, Rianne Esselink ${ }^{6}$ and Yasin Temel ${ }^{1,2 *}$ \\ ${ }^{1}$ Department of Neurosurgery, Maastricht Medical Center, Maastricht, Netherlands, ${ }^{2}$ Department of Neuroscience, \\ Maastricht University Medical Center, Maastricht, Netherlands, ${ }^{3}$ Department of Neurosurgery, Ondokuz Mayis University, \\ Samsun, Turkey, ${ }^{4}$ Department of Neurology, Maastricht Medical Center, Maastricht, Netherlands, ${ }^{5}$ Department of \\ Neurosurgery, Donders Institute for Cognition, Brain and Behaviour, Radboud University Medical Center, Nijmegen, \\ Netherlands, ${ }^{6}$ Department of Neurology, Donders Institute for Cognition, Brain and Behaviour, Radboud University Medical \\ Center, Nijmegen, Netherlands
}

Keywords: microelectrode recording, magnetic resonance imaging, subthalamic nucleus, deep brain stimulation, Parkinson's disease

\section{The Question}

High frequency stimulation of the subthalamic nucleus (STN) is an effective treatment for patients with Parkinson's disease (PD) (Odekerken et al., 2012; Kocabicak et al., 2013; Schuepbach et al., 2013). The technique has been further refined throughout the years by improved magnetic resonance imaging (MRI) techniques, advanced neurophysiological recording possibilities, and

Edited by: Sidney A. Simon,

Duke University, USA

Reviewed by:

Hagai Bergman,

The Hebrew University of Jerusalem,

Israel

Ludvic Zrinzo,

UCL Institute of Neurology, UK

${ }^{*}$ Correspondence:

Yasin Temel,

y.temel@maastrichtuniversity.nl

Received: 10 March 2015

Accepted: 15 July 2015

Published: 11 August 2015

Citation:

Kocabicak E, Alptekin O, Ackermans

L, Kubben P, Kuijf M, Kurt E, Esselink $R$ and Temel $Y$ (2015) Is there still need for microelectrode recording now the subthalamic nucleus can be well visualized with high field and ultrahigh MR imaging?

Front. Integr. Neurosci. 9:46. doi: 10.3389/fnint.2015.00046 advances in hardware and software technology (Kocabicak and Temel, 2013). There are at least two major determining factors for an acceptable therapeutic outcome: patient selection (Deuschl et al., 2006) and the accuracy of targeting of the relatively small STN (Temel et al., 2005). The latter requires a state-of-the art stereotactic approach, adequate imaging facilities, and a detailed neurophysiological mapping of the target area. The preferred area within the STN is the motor part (thought to be located dorsolaterally in the STN), which can, be to some extent, identified by intraoperative multi-unit activity analyses, and MRI-based tractography (Zaidel et al., 2010; Brunenberg et al., 2011).

While the STN could not be visualized on MRI images when modern DBS of the STN surgeries started in Grenoble in 1993, nowadays its visualization has become a routine procedure for most centers offering DBS for patients with PD. While using intraoperative electrophysiology was evident in the beginning, now it is questioned whether it still has an essential added value. In this opinion article, we aim to provide an answer on the question whether or not electrophysiology still has a clinically relevant role in this era of advanced neuroimaging technology, which enables us to visualize both function and structure anatomy.

\section{Old Debate}

The discussion of whether or not to use intraoperative microelectrode recording (MER) is not a new one (Hariz, 2002). This discussion was perhaps less vivid when modern DBS started to be applied in patients with PD. The STN was an invisible target on MR images in most centers and MER was considered very helpful to find and delineate the boundaries of the target (Pollak et al., 1993; Limousin et al., 1995; Shamir et al., 2012). Since then things have changed. However, currently the STN can be directly visualized on T2 weighed and susceptibility weighed MR images. 
The imaging field progresses rapidly further with ultra-high field imaging modalities becoming now available for patients (Plantinga et al., 2014).

It is more than 15 years ago that that the visualization of the STN for DBS surgeries was described (Starr et al., 1999). Mostly, T2 weighed and inversion recovery MRI sequences have been used. In most of the patients, the predefined target on T2 weighed MR images was chosen for implantation after intraoperative electrophysiology and test-stimulation (Bejjani et al., 2000; Egidi et al., 2002; Starr et al., 2002). This meant that in most patients MRI images could reliably show the STN, except for the $y$ axis, in which microelectrode recording (MER) indicated that the STN extended more anteriorly than suggested by MRI (Hamani et al., 2005). Detailed volumetric analysis of MER-determined borders of the STN and MRI- defined borders in 22 patients (44 STN's), showed that MER-determined borders of the STN were exceeding the MRI signal (Schlaier et al., 2011). In addition, we examined the entry and exit borders of the STN on MRI images and with MER, using the probe's eye trajectory (Kocabicak et al., 2013). We found that T2 weighed MRI could reliably predict the electrophysiological entry and exit of the STN. Although these data confirm the accuracy of MRI in visualizing the STN, there are also limitations. There are known variations between the patients with respect to the $\mathrm{x}, \mathrm{y}$, and $\mathrm{z}$ planes, and the borders can sometimes be less clear, mainly toward the substantia nigra pars reticulata (SNr) (Hamani et al., 2005; Kocabicak et al., 2013).

\section{From Atlas-based to MRI Based Coordinates and from Single-electrode to Multiple-electrode Recordings}

In our previous series of 55 patients with $\mathrm{PD}$ who underwent DBS of the STN, atlas- based coordinates were used and in about one third of the patients the predefined target (central trajectory) was used for final electrode implantation, after MER and intraoperative test-stimulation (Temel et al., 2007). With applying individually adjusted coordinates based on T2 weighed MRI, the central trajectory was chosen in about two-thirds of the patients (Kocabicak et al., 2013; Tonge et al., in press). This has resulted in a clear reduction in operation time. Similar rates have been

\section{References}

Amirnovin, R., Williams, Z. M., Cosgrove, G. R., and Eskandar, E. N. (2006). Experience with microelectrode guided subthalamic nucleus deep brain stimulation. Neurosurgery 58(Suppl. 1), 96-102. doi: 10.1227/01.neu.0000192690.45680.c2

Aviles-Olmos, I., Kefalopoulou, Z., Tripoliti, E., Candelario, J., Akram, H., Martinez-Torres, I., et al. (2014). Long-term outcome of subthalamic nucleus deep brain stimulation for Parkinson's disease using an MRI-guided and MRI-verified approach. J. Neurol. Neurosurg. Psychiatry 85, 1419-1425. doi: 10.1136/jnnp-2013-306907

Bejjani, B. P., Dormont, D., Pidoux, B., Yelnik, J., Damier, P., Arnulf, I., et al. (2000). Bilateral subthalamic stimulation for Parkinson's disease by using threedimensional stereotactic magnetic resonance imaging and electrophysiological guidance. J. Neurosurg. 92, 615-625. doi: 10.3171/jns.2000.92.4.0615 reported by others with atlas-based (Amirnovin et al., 2006) and MRI-based targeting coordinates (Reck et al., 2012). The change from 1.5 to $3.0 \mathrm{~T}$ has also improved the accuracy of targeting (Toda et al., 2009; Kerl et al., 2012).

Another development has been the change of single-electrode to multiple-electrode intra-operative electrophysiological recordings (Temel et al., 2007). The latter provides more detailed information about the electrophysiological boundaries of the STN; however, implantation of several electrodes at one time might increase the risk of bleeding. We found that the simultaneous implantation of multiple electrodes did not cause more bleedings or other major intracranial complication. The use of multiple electrodes resulted in better motor results when compared with patients who underwent DBS of the STN guided with a single recording electrode. There are reports, however, suggesting increased risk of hemorrhage due to MER (Ben-Haim et al., 2009; Xiaowu et al., 2010).

\section{Back to the Question}

Is intra-operative electrophysiology necessary to find the STN? Our answer is no based on the advances in MRI technology.

In line with this experienced DBS centers have shown good outcome with a MRI-guided approach (Ostrem et al., 2013; Aviles-Olmos et al., 2014). So should we abandon MER then? In our centers, we have decided not to abandon it for a number of reasons. Even in experienced centers, in about two-thirds of the cases, the predefined target is chosen for final implantation. In one-third, an alternative trajectory is needed. With MER, alternative trajectories are immediately available. The trajectory with the second longest and, if needed, the third longest STN activity can be used as alternative trajectories. Two other less common reasons to use intra-operative electrophysiology can be an unexpected error in the stereotactic approach or a shift caused by excessive CSF leakage or a hematoma (Reck et al., 2012).

\section{Acknowledgments}

OA is an employee of Medtronic and has a scientific affiliation at Maastricht University. 
Hamani, C., Richter, E. O., Andrade-Souza, Y., Hutchison, W., Saint- Cyr, J. A., and Lozano, A. M. (2005). Correspondence of microelectrode mapping with magnetic resonance imaging for subthalamic nucleus procedures. Surg. Neurol. 63, 249-253. doi: 10.1016/j.surneu.2004.05.036

Hariz, M. I. (2002). Safety and risk of microelectrode recording in surgery for movement disorders. Stereotact. Funct. Neurosurg. 78, 146-157. doi: $10.1159 / 000068960$

Kerl, H. U., Gerigk, L., Pechlivanis, I., Al-Zghloul, M., Groden, C., and Nölte, I. (2012). The subthalamic nucleus at 3.0 Tesla: choice of optimal sequence and orientation for deep brain stimulation using a standard installation protocol: clinical article. J. Neurosurg. 117, 1155-1165. doi: 10.3171/2012.8.JNS111930

Kocabicak, E., Aygun, D., Ozaydin, I., Jahanshahi, A., Tan, S., Onar, M., et al. (2013). Does probe's eye subthalamic nucleus length on T2W MRI correspond with microelectrode recording in patients with deep brain stimulation for advanced Parkinson's disease? Turk. Neurosurg. 23, 658-665. doi: 10.5137/1019-5149.JTN.8328-13.0

Kocabicak, E., and Temel, Y. (2013). Deep brain stimulation of the subthalamic nucleus in Parkinson's disease: surgical technique, tips, tricks and complications. Clin. Neurol. Neurosurg. 115, 2318-2323. doi: 10.1016/j.clineuro.2013.08.020

Limousin, P., Pollak, P., Benazzouz, A., Hoffmann, D., Le Bas, J. F., Broussolle, E., et al. (1995). Effect of parkinsonian signs and symptoms of bilateral subthalamic nucleus stimulation. Lancet 345, 91-95. doi: 10.1016/S0140-6736(95)90062-4

Odekerken, V. J., van Laar, T., Staal, M. J., Mosch, A., Hoffmann, C. F., Nijssen, P. C., et al. (2012). Subthalamic nucleus versus globus pallidus bilateral deep brain stimulation for advanced Parkinson's disease (NSTAPS study): a randomized controlled trial. Lancet Neurol. 12, 37-44. doi: 10.1016/S1474-4422(12)70264-8

Ostrem, J. L., Galifianakis, N. B., Markun, L. C., Grace, J. K., Martin, A. J., Starr, P. A. et al. (2013). Clinical outcomes of PD patients having bilateral STN DBS using high-field interventional MR-imaging for lead placement. Clin. Neurol. Neurosurg. 115, 708-712. doi: 10.1016/j.clineuro.2012.08.019

Plantinga, B. R., Temel, Y., Roebroeck, A., Uludag, K., Ivanov, D., Kuijf, M. L., et al. (2014). Ultra-high field magnetic resonance imaging of the basal ganglia and related structures. Front. Hum. Neurosci. 8:876. doi: 10.3389/fnhum.2014.00876

Pollak, P., Benabid, A. L., Gross, C., Gao, D. M., Laurent, A., Benazzouz, A., et al. (1993). Effects of the stimulation of the subthalamic nucleus in Parkinson disease. Rev. Neurol. (Paris) 149, 175-176.

Reck, C., Maarouf, M., Wojtecki, L., Groiss, S. J., Florin, E., Sturm, V., et al. (2012). Clinical outcome of subthalamic stimulation in Parkinson's disease is improved by intraoperative multiple trajectories microelectrode recording. J. Neurol. Surg. A Cent. Eur. Neurosurg. 73, 377-386. doi: 10.1055/s-0032-1326957

Schlaier, J. R., Habermeyer, C., Warnat, J., Lange, M., Janzen, A., Hochreiter, A., et al. (2011). Discrepancies between the MRI- and the electrophysiologically defined subthalamic nucleus. Acta Neurochir. 153, 2307-2318. doi: 10.1007/s00701-011-1081-7

Schuepbach, W. M., Rau, J., Knudsen, K., Volkmann, J., Krack, P., Timmermann, L., et al. (2013). Neurostimulation for Parkinson's disease with early motor complications. N. Engl. J. Med. 368, 610-622. doi: 10.1056/NEJMoa1205158

Shamir, R. R., Zaidel, A., Joskowicz, L., Bergman, H., and Israel, Z. (2012). Microelectrode recording duration and spatial density constraints for automatic targeting of the subthalamic nucleus. Stereotact. Funct. Neurosurg. 90, 325-334. doi: 10.1159/000338252

Starr, P. A., Christine, C. W., Theodosopoulos, P. V., Lindsey, N., Byrd, D., Mosley, A., et al. (2002). Implantation of deep brain stimulators into the subthalamic nucleus: technical approach and magnetic resonance imagingverified lead locations. J. Neurosurg. 97, 370-387. doi: 10.3171/jns.2002.97. 2.0370

Starr, P. A., Vitek, J. L., DeLong, M., and Bakay, R. A. (1999). Magnetic resonance imaging-based stereotactic localization of the globus pallidus and subthalamic nucleus. Neurosurgery 44, 303-313. doi: 10.1097/00006123-199902000-00031

Temel, Y., Blokland, A., Steinbusch, H. W., and Visser-Vandewalle, V. (2005). The functional role of the subthalamic nucleus in cognitive and limbic circuits. Prog. Neurobiol. 76, 393-413. doi: 10.1016/j.pneurobio.2005.09.005

Temel, Y., Wilbrink, P., Duits, A., Boon, P., Tromp, S., Ackermans, L., et al. (2007). Single electrode and multiple electrode guided electrical stimulation of the subthalamic nucleus in advanced Parkinson's disease. Neurosurgery 61 (5 Suppl. 2), 346-355. doi: 10.1227/01.neu.0000303993.82149.98

Toda, H., Sawamoto, N., Hanakawa, T., Saiki, H., Matsumoto, S., Okumura R., et al. (2009). A novel composite targeting method using high-field magnetic resonance imaging for subthalamic nucleus deep brain stimulation. J. Neurosurg. 111, 737-745. doi: 10.3171/2008.12.JNS0861

Tonge, M., Kocabicak, E., Ackermans, L., Kuijf, M., and Temel, Y. (in press). Final electrode position in subthalamic nucleus deep brain stimulation surgery: a comparison of indirect and direct targeting methods. Turk Neurosurg. doi: 10.5137/1019-5149.JTN.13739-14.1

Xiaowu, H., Xiufeng, J., Xiaoping, Z., Bin, H., Laixing, W., Yiqun, C., et al. (2010). Risks of intracranial hemorrhage in patients with Parkinson's disease receiving deep brain stimulation and ablation. Parkinsonism Relat. Disord. 16, 96-100. doi: 10.1016/j.parkreldis.2009.07.013

Zaidel, A., Spivak, A., Grieb, B., Bergman, H., and Israel, Z. (2010). Subthalamic span of beta oscillations predicts deep brain stimulation efficacy for patients with Parkinson's disease. Brain 133, 2007-2021. doi: 10.1093/brain/ awq144

Conflict of Interest Statement: The Review Editor Dr. Hagai Bergman declares that, despite chairing meetings for the Mediterranean Neuroscience Society as well as organizing an academic course with Author Dr. Yasin Temel (as a joint collaboration between Maastricht University Medical Center and the Mediterranean Neuroscience Society) the review process was handled objectively. The authors declare that the research was conducted in the absence of any commercial or financial relationships that could be construed as a potential conflict of interest.

Copyright (C) 2015 Kocabicak, Alptekin, Ackermans, Kubben, Kuijf, Kurt, Esselink and Temel. This is an open-access article distributed under the terms of the Creative Commons Attribution License (CC BY). The use, distribution or reproduction in other forums is permitted, provided the original author(s) or licensor are credited and that the original publication in this journal is cited, in accordance with accepted academic practice. No use, distribution or reproduction is permitted which does not comply with these terms. 